\title{
DEVELOPMENT AND VALIDATION OF A LC-METHOD FOR THE DETERMINATION OF PHENOLS IN A PHARMACEUTICAL FORMULATION CONTAINING EXTRACTS FROM Stryphnodendron adstringens
}

\author{
Ana Cristina Isler, Gisely Cristiny Lopes, Mara Lane Carvalho Cardoso e João Carlos Palazzo de Mello* \\ Departamento de Farmácia e Farmacologia, Universidade Estadual de Maringá, Av. Colombo, 5790, 87020-900 Maringá - PR, Brasil \\ Luís Carlos Marques \\ Campus Maria Cândida, Universidade Bandeirante de São Paulo, Rua Maria Cândida, 1813, 02071-013 São Paulo - SP, Brasil
}

Recebido em 22/9/09; aceito em 28/1/10; publicado na web em 3/5/10

\begin{abstract}
A sensitive RP-HPLC method with UV detection successfully measured phenol(s) in an ointment containing 3\% Stryphnodendron adstringens extract. Chromatography used acetonitrile ( $0.05 \%$ trifluoroacetic acid):water $(0.05 \%$ trifluoroacetic acid) (v/v), flow rate $0.8 \mathrm{~mL}$ $\mathrm{min}^{-1}$. Quantitation was accomplished by the external-standard method. Linearity for 2.00 to $16.00 \mu \mathrm{g} \mathrm{mL}^{-1}$ (gallic acid) and 1.14 to 18.24 $\mu \mathrm{g} \mathrm{mL}^{-1}$ (gallocatechin) was established. Intra- and inter-day precision levels were under 5\%. LOD and LOQ were 0.231 and $0.770 \mu \mathrm{g} \mathrm{mL}{ }^{-1}$ (gallic acid) and 0.151 and $0.504 \mu \mathrm{g} \mathrm{mL}^{-1}$ (gallocatechin), respectively. Determination of phenols was unaffected by product excipients.
\end{abstract}

Keywords: Stryphnodendron adstringens; HPLC; method validation.

\section{INTRODUCTION}

Stryphnodendron adstringens (Mart.) Coville is a medicinal plant that grows in the Cerrado (savanna) of Brazil and is commonly known as 'barbatimão'. The stem bark of $S$. adstringens is mentioned in the Brazilian Pharmacopoeia, and contains at least $8 \%$ total tannins. ${ }^{1}$ Decoctions or infusions of the crude drug are traditionally used by the native population of Brazil to treat wounds, leucorrhea and diarrhea, and as an anti-inflammatory agent. ${ }^{1}$ Previous investigations of the chemical composition of $S$. adstringens have indicated the occurrence of several flavan-3-ols, prodelphinidin and prorobinetinidin compounds, including several new compounds. ${ }^{1-4}$ The wound-healing, ${ }^{5}$ anti-inflammatory, ${ }^{6}$ antimicrobial, ${ }^{7,8}$ antiulcer ${ }^{9}$ and antinociceptive activities ${ }^{10}$ of an acetone-soluble fraction, ethyl-acetate or water semipurified fraction from the stem bark were attributed to the presence of proanthocyanidins.

Plant polyphenols are secondary metabolites that are found widely in medicinal plants and foods, and can be classified as condensed proanthocyanidins, galloyl and hexahydroxydiphenoyl esters, and phlorotannins. ${ }^{11}$ These polyphenols show several kinds of pharmacological activity, including anti-inflammatory, ${ }^{12}$ antimicrobial ${ }^{13}$ and antiulcer, ${ }^{14}$ and are of technological importance because of their antioxidant activity ${ }^{15}$ and protein-binding potential. ${ }^{11}$ The basic characteristic that gives plant polyphenols their biological properties seems to be the high concentration of ortho-phenol-hydroxyl groups. ${ }^{11}$

Many studies have been carried out on extracts of S. adstringens. However, the validation of an efficient analytical method is an integral part of the quality control of the source material, in order to guarantee the safety and effectiveness of the end product as required by the Brazilian regulating agency in Regulation RDC 48/2004. ${ }^{16}$

Several HPLC methods have been described for the analysis of phenolic compounds and/or plant polyphenols, including gallic acid and gallocatechin, in medicinal plants. ${ }^{17-21}$ However, only a few methods have been reported for the determination of plant polyphenols (condensed proanthocyanidins) in commercial plant extracts. ${ }^{22,23}$ To the best of our knowledge, so far no systematic LC-method for the determination of plant polyphenols in pharmaceutical formulations has been published.

\footnotetext{
*e-mail:mello@uem.br
}

This paper reports a sensitive method for RP-HPLC determination that employs UV detection, which is useful for routine quality control of gallic acid and gallocatechin in a pharmaceutical formulation (ointment) containing an extract of $S$. adstringens. The method was validated by the parameters of specificity, linearity, detection and quantitation limits, accuracy, precision and robustness.

\section{EXPERIMENTAL}

\section{Chemicals and reagents}

All reagents and solvents were of analytical and HPLC grade, including ethyl acetate and trifluoroacetic acid (TFA) (Merck, Darmstadt, Germany). Ultra-pure water obtained using a Milli-Q ${ }^{\circledR}$ UFPlus apparatus (Millipore, Bedford, MA, USA) with conductivity of $18 \mathrm{~m} \Omega$ was used in all experiments. Gallic acid and gallocatechin (Sigma, USA) of the highest grade (purity $>99.0 \%$ ) were used as external standards. Gallic acid and gallocatechin were determined in a pharmaceutical formulation (ointment). The ointment was prepared using $3 \%$ of the extract of S. adstringens, which contains $50 \%$ total tannins. The placebo formulations were prepared without the extract.

\section{Instrumentation and chromatographic conditions}

The analyses were carried out using a HPLC system (Gilson, USA) consisting of a solvent delivery pump (Model 321), a variable wavelength UV/VIS detector (Model 156), a manual injection valve (Rheodyne $^{\circledR}$, USA) with a $20 \mu \mathrm{L}$ loop, degasser (Model 184), and thermostatted column compartment (Model 831). Data collection and analyses were performed using UniPoint ${ }^{\mathrm{TM}}$ LC System Software (Gilson, Villiers-le-Bel, France). A gradient elution was performed on a Phenomenex ${ }^{\circledR}$ Gemini C-18 column (250 mm x $4.6 \mathrm{~mm}$ i.d.) (Phenomenex International, USA), $5 \mu \mathrm{m}$ particle size, Phenomenex ${ }^{\circledR}$ SecurityGuard ${ }^{\mathrm{TM}}$ (C-18 cartridge) $(20 \mathrm{~mm}$ x $4.6 \mathrm{~mm}$ i.d.). The mobile phase consisted of water ( $0.05 \%$ TFA) as solvent A and acetonitrile $(0.05 \%$ TFA) as solvent B, and both were degassed and filtered through a $0.45 \mu \mathrm{m}$ pore size filter (Millipore, Bedford, USA). Separations were effected by a linear gradient as follows: 0 min $5 \% \mathrm{~B}$; $10 \min 19.35 \% \mathrm{~B} ; 13.5 \min 25 \% \mathrm{~B} ; 23 \min 38 \% \mathrm{~B} ; 25 \min 75 \% \mathrm{~B}$, followed by a $10 \mathrm{~min}$ re-equilibration time. The mobile phase flow 
rate was $0.8 \mathrm{~mL} \mathrm{~min}^{-1}$ and the injection volume was $100 \mu \mathrm{L}$. The chromatographic runs were carried out at $28{ }^{\circ} \mathrm{C}$. UV detection was performed at $210 \mathrm{~nm}$.

For the determination of peak purity, the Varian ProStar module (Varian, Palo Alto, CA, USA) with ProStar 210 Solvent Delivery and a ProStar 335 HPLC-DAD was used.

The statistical analyses of the data were performed by means of Statistica 7.0 Software (Statsoft Inc., Tulsa, OK, USA).

\section{Sample preparation and purification}

An accurately weighed portion of ointment ( $4.17 \mathrm{~g})$ equivalent to $250 \mathrm{mg}$ of the extract of $S$. adstringens was dissolved in $20 \mathrm{~mL}$ water, extracted with $500 \mathrm{~mL}$ ethyl acetate, and allowed to rest in a freezer $\left(-18{ }^{\circ} \mathrm{C}\right)$ for $15 \mathrm{~min}$, for total separation of the phases. The ethyl-acetate phase was concentrated under reduced pressure in a rotavapor, yielding a brown residue (RES). The RES was dissolved in methanol:water (50:50, v/v) to $100 \mathrm{~mL}$ (Stock Solution-SS). Dilutions of the SS were prepared to obtain the following theoretical concentrations: $20.85 ; 33.36$ and $41.70 \mathrm{mg} \mathrm{mL}^{-1}$ corresponding to the ointment. Next, the flask was shaken for $5 \mathrm{~min}$, and the sample was filtered through a $0.5 \mu \mathrm{m}$ membrane filter (Millipore, Bedford, MA, USA). The sample injection volume was $100 \mu \mathrm{L}$.

\section{Preparation of standard solutions}

\section{Preparation of gallic acid calibration standards}

A gallic acid stock solution of $100 \mu \mathrm{g} \mathrm{mL}^{-1}$ was prepared in methanol:water $(1: 1 \mathrm{v} / \mathrm{v})$ using the gallic acid reference standard. Calibration standard solutions at five levels were prepared by serially diluting the stock solution to concentrations of $2.00 ; 4.00 ; 8.00$; 14.00; and $16.00 \mu \mathrm{g} \mathrm{mL}^{-1}$. The samples were filtered through a 0.5 $\mu \mathrm{m}$ membrane (Millipore, Bedford, MA, USA) prior to injection. Each analysis was repeated five times, and the calibration curves were fitted by linear regression.

\section{Preparation of gallocatechin calibration standards}

A gallocatechin stock solution of $152 \mu \mathrm{g} \mathrm{mL}^{-1}$ was prepared in methanol:water $(1: 1 \mathrm{v} / \mathrm{v})$ using the gallocatechin reference standard. Calibration standard solutions at five levels were prepared by serially diluting the stock solution to concentrations of $1.14 ; 2.28 ; 4.56$; 9.12 and $18.24 \mu \mathrm{g} \mathrm{mL}^{-1}$. The samples were filtered through a $0.5 \mu \mathrm{m}$ membrane (Millipore, Bedford, MA, USA) prior to injection. Each analysis was repeated five times, and the calibration curves were fitted by linear regression.

\section{Validation parameters}

The method was validated by regulation RE 899/2003 of the National Health Surveillance Agency, Brazil ${ }^{24}$ and the ICH guidelines. ${ }^{25}$ The following validation characteristics were assessed: specificity, linearity, limit of detection and quantitation, accuracy, precision and robustness. ${ }^{26}$

\section{Specificity}

The specificity, defined as the ability of the method to measure the analyte accurately and specifically in the presence of components in the sample matrix, was determined by analysis of chromatograms of standards, ointment, and placebo formulation. The Varian Prostar system described above was employed.

\section{Linearity}

Standard calibration curves were prepared with five determinations over a concentration range of $2-16 \mu \mathrm{g} \mathrm{mL}^{-1}$ for gallic acid, and over a range of 1.14-18.24 $\mu \mathrm{g} \mathrm{mL}^{-1}$ for gallocatechin, processed separately and run in duplicate daily on 3 consecutive days. The data for peak area versus drug concentration were treated by linear regression analysis.

\section{Sensitivity}

The LOD and LOQ were determined from the calibration curves of the gallic acid and gallocatechin standards. LOD was calculated according to the expression $3 \sigma / \mathrm{S}$, where $\sigma$ is the standard deviation of the response and $S$ is the slope of the calibration curve. LOQ was established by using the expression $10 \sigma / \mathrm{S}$.

\section{Accuracy}

The accuracy was evaluated by adding known amounts of the extract at $50 \%$ in the placebo ointment at three concentrations (low, medium and high). The theoretical concentrations of the gallic acid and gallocatechin were, respectively: $4.52,9.03$ and $13.55 \mu \mathrm{g} \mathrm{mL}^{-1}$, and $6.09,12.18$ and $18.27 \mu \mathrm{g} \mathrm{mL}^{-1}$. The recovery was determined by comparing the results of the analyses of the fortified samples after the extraction process, with the nominal value by means of Student's $t$ test. The determinations were carried out in triplicate.

\section{Precision}

The test of repeatability was carried out using three determinations for each corresponding concentration of the ointment (20.85, 33.36 and $41.70 \mathrm{mg} \mathrm{mL}^{-1}$ ), the concentration of $41.70 \mathrm{mg} \mathrm{mL}^{-1}$ being the SS itself. The areas of the peaks corresponding to the substances of interest were determined at $210 \mathrm{~nm}$.

The intermediate precision was determined four days later with SS $\left(41.70 \mathrm{mg} \mathrm{mL}^{-1}\right)$, with six replicates.

Precision was expressed as the relative standard deviations (\% RSD) of the concentrations of gallic acid and gallocatechin.

\section{Robustness}

The robustness of the method was evaluated by analyzing the data for the system suitability parameter after varying the HPLC wavelength from $210 \mathrm{~nm}$ to $212 \mathrm{~nm} .{ }^{26}$

\section{RESULTS AND DISCUSSION}

Several reversed-phase HPLC methods using various mixtures of acetonitrile/water or methanol/water with acetic acid, phosphoric acid or TFA have been used for analysis of plant polyphenols and also condensed tannins, in crude plant materials and food products. ${ }^{18,20,21,27,28}$ Up to the present, no published method is available for the simultaneous determination of gallic acid and gallocatechin in pharmaceutical formulations. The elimination of high-molecularweight polyphenolic substances from the plant extract is critically important because of the interaction that these substances show with the stationary phase, which can seriously damage the analytical column, leading to interference with the chromatographic process. Therefore, in this study, the extraction of phenolic compounds (gallic acid, gallocatechin and others) from the ointment was optimized by using a mixture of water:ethyl acetate.

The goal of optimization was to develop a chromatographic method for two phenolic compounds (gallic acid and gallocatechin) and with good peak resolution between the two, with the most efficient analysis time. The use of the C-18 Column (Phenomenex) allowed us to explore a $\mathrm{pH}$ range between 1.0 and 4.0. In developing the method, addition of 0.05 to $0.1 \%$ TFA, which suppresses the ionization of phenol groups, to all the solvent systems improved the separation of the phenol compounds. ${ }^{21}$ Therefore, the use of TFA is essential for complete separation. ${ }^{29}$ The gallic acid and gallocatechin in the 
ointment were identified by comparing their retention times with the chromatogram of the standards and by re-chromatography. The chromatographic conditions described in this method were arrived at after investigating several mobile phases consisting of mixtures of acetonitrile, and methanol and water in different ratios. Symmetrical, sharp and well-resolved peaks were obtained for gallic acid and gallocatechin. A typical chromatogram obtained from the samples is shown in Figure 1. There were no peaks due to other, minor coextracted materials interfering with the gallic acid and gallocatechin. The retention times for gallic acid and gallocatechin were 8.39 and $10.82 \mathrm{~min}$, respectively.

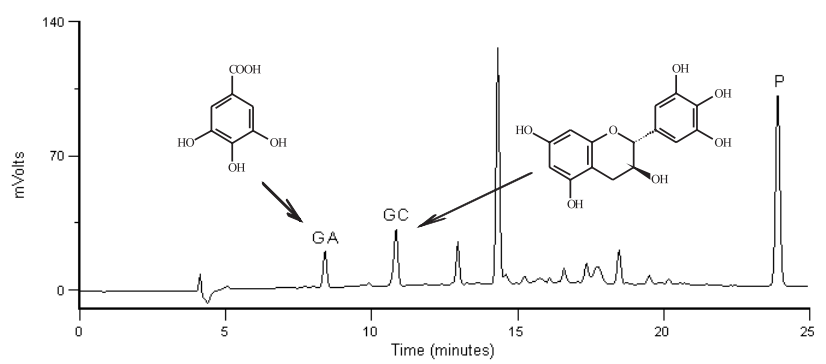

Figure 1. Chromatogram of the gallic acid (GA), gallocatechin (GC), and placebo $(P)$ in the ointment. Chromatographic conditions: column Phenomenex, Gemini C-18 (250 mm x $4.6 \mathrm{~mm}$ i.d., $5 \mu \mathrm{m}$ ), Security Guard (RP-cartridge) (20 mm $x 4.6 \mathrm{~mm}$ i.d., $5 \mu \mathrm{m}$ ); mobile phase: water (TFA 0.05\%) A and acetonitrile (TFA $0.05 \%$ ) B; 0 min 5\% B in A; $10 \min 19.35 \%$ B; $13.5 \min 25 \%$ B; $23 \mathrm{~min} 38 \% \mathrm{~B} ; 25 \mathrm{~min} 75 \% \mathrm{~B}$; flow-rate, $0.8 \mathrm{~mL} \mathrm{~min}^{-1}$; detection at $210 \mathrm{~nm}$

The selectivity of the assay was determined by placebo analysis. Placebos of an ointment containing all the normal ingredients except the extract of $S$. adstringens were prepared. They were treated in the same manner as the normal samples, and samples were injected for study of interference by other ingredients in the selectivity of the gallic acid and gallocatechin separation (Figure 1). The peak at $23.88 \mathrm{~min}$ (P), which corresponds to the placebo component, demonstrated the specificity of the method, because the peak was found outside of the retention time of the substances analyzed (Figure 2). The resolution of the peaks of gallic acid and gallocatechin in the sample, after analysis of the chromatograms by means of a chromatograph with a photodiode-array detector, indicated the specificity of the method (data not shown). The UV spectra of the substances (gallic acid and gallocatechin) confirmed the absence of impurities, because these did not change between the beginning and end of elution.

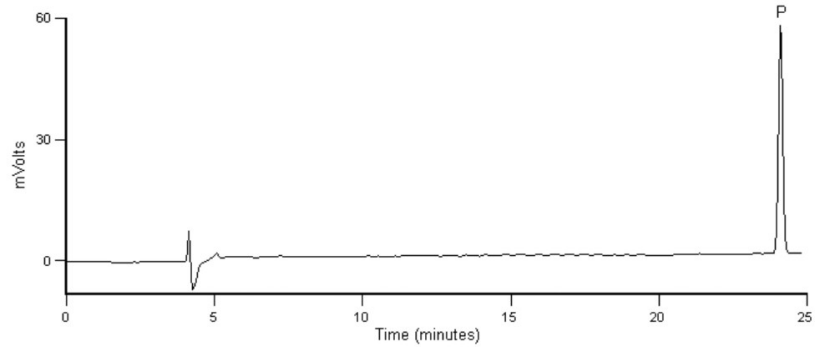

Figure 2. Chromatogram of the placebo $(P)$ sample

Based on $1 / x$ weighted linear regression analysis, the responses for both standards in related concentration ranges were linear. The calibration equations were $\mathrm{y}=38002 x+7991.81\left(n=5, r^{2}=0.9992\right)$ for gallic acid and $\mathrm{y}=52602 x-6458.47\left(n=5, r^{2}=0.9998\right)$ for gallocatechin. The RSDs of the slopes were $\leq 5 \%$ for both analytes $(n=5)$. Table 1 shows the back-fit calculations for curve data for the standards used in the validation runs, as well as the precision and accuracy of the back-fit calculations.

Table 1. Curve parameter summary and back-calculated calibration curve concentrations for gallic acid and gallocatechin

\begin{tabular}{lccccc}
\hline \multicolumn{5}{c}{ Gallic acid concentration $\left(\mu \mathrm{g} \mathrm{mL}^{-1}\right)$} \\
Mean \pm S.D. $2.04 \pm 0.06$ & $4.02 \pm 0.19$ & $7.98 \pm 0.00$ & $11.80 \pm 0.0616 .15 \pm 0.06$ \\
R.S.D. $(\%)$ & 2.95 & 4.85 & 0.06 & 0.58 & 0.40 \\
\hline \multicolumn{5}{c}{ Gallocatechin concentration $\left(\mu \mathrm{gL}^{-1}\right)$} \\
& 1.52 & 3.04 & 6.08 & 12.16 & 24.32 \\
Mean \pm S.D. $1.50 \pm 0.06$ & $3.15 \pm 0.02$ & $6.07 \pm 0.10$ & $12.00 \pm$ & 0.09 & $24.38 \pm 0.14$ \\
R.S.D. (\%) & 4.10 & 0.70 & 1.65 & 0.78 & 0.58 \\
\hline Mean \pm S.D. $(n=$ 5). R.S.D. \% $=(($ S.D. $/$ mean $) \times 100)$.
\end{tabular}

The LOD, defined as the lowest concentration of gallic acid and gallocatechin in an ointment that can be detected but not necessarily quantified under the stated experimental conditions, was 0.231 and $0.151 \mu \mathrm{g} \mathrm{mL}^{-1}$, respectively. The LOQ, defined as the lowest concentration of gallic acid and gallocatechin in an ointment that can be determined with acceptable precision and accuracy, was 0.770 and $0.504 \mu \mathrm{g} \mathrm{mL}^{-1}$, respectively.

Accuracy was determined by analyzing a sample of known concentration and comparing the measured value with the true value, using the method of standard addition. Table 2 summarizes the results for accuracy, expressed as the percentage of recovery and relative standard deviation (RSD) for the two approaches. The method showed good accuracy.

Table 2. Results for the determination of accuracy by analyzing the gallic acid and gallocatechin in known concentrations

\begin{tabular}{|c|c|c|c|c|}
\hline $\begin{array}{l}\text { Theoretical } \\
\text { concentration } \\
\mu \mathrm{g} \mathrm{mL} \mathrm{L}^{-1}\end{array}$ & $\begin{array}{l}\text { Amount } \\
\text { recovered } \\
\left(\mu \mathrm{g} \mathrm{mL} L^{-1}\right) \\
\end{array}$ & $\%$ Recovered & Mean $(\%) \pm$ S.D. & $\begin{array}{l}\% \\
\text { R.S.D. }\end{array}$ \\
\hline \multicolumn{5}{|l|}{ Gallic acid } \\
\hline 4.52 & $\begin{array}{l}4.20 \\
4.17 \\
4.13\end{array}$ & $\begin{array}{l}92.88 \\
92.32 \\
91.43\end{array}$ & $92.21 \pm 0.73$ & 0.79 \\
\hline 9.03 & $\begin{array}{l}8.68 \\
8.73 \\
8.74\end{array}$ & $\begin{array}{l}96.09 \\
96.62 \\
96.73\end{array}$ & $96.48 \pm 0.34$ & 0.36 \\
\hline 13.55 & $\begin{array}{l}14.07 \\
13.97 \\
14.12\end{array}$ & $\begin{array}{l}103.82 \\
103.12 \\
104.23\end{array}$ & $103.72 \pm 0.56$ & 0.54 \\
\hline \multicolumn{5}{|l|}{ Gallocatechin } \\
\hline 6.09 & $\begin{array}{l}5.57 \\
5.64 \\
5.63\end{array}$ & $\begin{array}{l}91.51 \\
92.67 \\
92.36\end{array}$ & $92.18 \pm 0.60$ & 0.65 \\
\hline 12.18 & $\begin{array}{l}11.06 \\
11.08 \\
11.16\end{array}$ & $\begin{array}{l}90.77 \\
90.93 \\
91.61\end{array}$ & $91.11 \pm 0.45$ & 0.49 \\
\hline 18.27 & $\begin{array}{l}17.41 \\
17.40 \\
17.49\end{array}$ & $\begin{array}{l}95.25 \\
95.19 \\
95.71\end{array}$ & $95.38 \pm 0.28$ & 0.30 \\
\hline
\end{tabular}

The results obtained from the analyses of the precision are listed in Tables 3 and 4, as mean recovery (\%). The data show that there were no significant differences between the assay results either within-day or between days, indicating that the precision of the proposed method was good (RSD less than $2 \%$ ). 
Table 3. Summary of repeatability (intra-day) for gallic acid and gallocatechin

\begin{tabular}{lcc}
\hline Spike level $\left(\mathrm{mg} \mathrm{mL}^{-1}\right)$ & \multicolumn{2}{c}{$\begin{array}{c}\text { Intra-day mean } \pm \operatorname{RSD}(\%)(n=3) \\
\text { Gallic acid }\end{array}$} \\
\hline 41.70 & $0.244 \pm 0.00(0.71)^{\mathrm{b}}$ & $0.288 \pm 0.00(0.53)^{\mathrm{b}}$ \\
33.36 & $0.198 \pm 0.00(0.29)^{\mathrm{a}, \mathrm{b}}$ & $0.236 \pm 0.00(0.73)^{\mathrm{b}}$ \\
20.85 & $0.125 \pm 0.00(1.39)^{\mathrm{a}, \mathrm{b}}$ & $0.147 \pm 0.00(0.78)^{\mathrm{a}, \mathrm{b}}$ \\
\hline
\end{tabular}

apeak with retention time observed with smallest area of LOD; ${ }^{b}$ peak with retention time observed with smallest area of LOQ

Table 4. Summary of intermediate precision (inter-day) for gallic acid and gallocatechin

\begin{tabular}{|c|c|c|}
\hline \multirow{2}{*}{ Spike level $\left(\mathrm{mg} \mathrm{mL}^{-1}\right)$} & \multicolumn{2}{|c|}{ Inter-day mean \pm RSD $(\%)(n=3)$} \\
\hline & Gallic acid & Gallocatechin \\
\hline 41.70 & $0.239 \pm 0.00(0.78)^{\mathrm{a}}$ & $0.288 \pm 0.00(1.61)^{\mathrm{a}}$ \\
\hline
\end{tabular}

${ }^{\text {a }}$ peak with retention time observed with smallest area of LOQ

To ensure that the HPLC method is insensitive to minor changes in the experimental conditions, it is important to demonstrate the robustness of the method. ${ }^{26}$ When the wavelength was changed by 2 $\mathrm{nm}$, from 210 to $212 \mathrm{~nm}$, this alteration caused no significant change in resolution between gallic acid and gallocatechin. This demonstrated the robustness of the method, under the conditions evaluated.

In conclusion, the HPLC method developed to analyze polyphenol compounds in an ointment was specific, linear, accurate, precise, and robust (under the conditions evaluated). A reversed-phase HPLC method allowed the simultaneous detection and quantitation of both gallic acid and gallocatechin in a specific pharmaceutical formulation (ointment).

The validation procedure confirmed that this is an appropriate method for quality control when an extract of Stryphnodendron adstringens containing $50 \%$ tannins is used in an ointment at a concentration of $3 \%$, in a pharmaceutical formulation.

\section{ACKNOWLEDGMENTS}

The authors are grateful for financial support from Capes, FINEP and CNPq, INCT_if, Fundação Araucária, and for material support from Apsen Farmacêutica S.A. Our gratitude to Dr. J. W. Reid for revising the English text. The valuable observations of anonymous reviewers and Associate Editor contributed significantly to improvements in the manuscript.

\section{REFERENCES}

1. Mello, J. P.; Petereit, F.; Nahrstedt, A.; Phytochemistry 1996, 41, 807.

2. Mello, J. P.; Petereit, F.; Nahrstedt, A.; Phytochemistry 1996, 42, 857.

3. Mello, J. C. P.; Petereit, F.; Nahrstedt, A.; Phytochemistry 1999, 51, 1105.

4. Lopes, G. C.; Machado, F. A. V.; Toledo, C. E. M.; Sakuragui, C. M.; Mello, J. C. P.; Biochem. Syst. Ecol. 2008, 36, 925.

5. Palermo, D.; Pereira, L. C. M. S.; Mello, J. C. P.; Hernandes, L.; Arq. Apadec. 2002, 6, 2.

6. Audi, E. A.; Toledo, C. E. M.; Santos, F. S.; Bellanda, P. R.; Prado, W. A.; Ueda-Nakamura, T.; Nakamura, C. V.; Sakuragui, C. M.; Amado, C. A. B.; Mello, J. C. P.; Acta Farm. Bonaerense 2004, 23, 328.
7. Ishida, K.; Mello, J. C. P.; Cortez, D. A. G.; Dias Filho, B. P.; UedaNakamura, T.; Nakamura, C. V.; J. Antimicrob. Chemother. 2006, 58, 942.

8. Ishida, K.; Rozental, S.; Mello, J. C. P.; Nakamura, C. V.; Ann. Clin. Microbiol. Antimicrob. 2009, 8, 29.

9. Audi, E. A.; Toledo, D. P.; Peres, P. G.; Kimura, E.; Pereira, W. K. V.; Mello, J. C. P.; Nakamura, C. V.; Prado, W. A.; Cuman, R. K. N.; Bersani-Amado, C. A.; Phytother. Res. 1996, 13, 264.

10. Melo, J. O.; Endo, T. H.; Bersani-Amado, L. E.; Svidzinski, A. E.; Baroni, S.; Mello, J. C. P.; Bersani-Amado, C. A.; Braz. J. Pharm. Sci. 2007, 43, 465 .

11. Haslam, E.; Practical Polyphenolics: From Structure to Molecular Recognition and Physiological Action, Cambridge University Press: Cambridge, 1998.

12. Hou, D.; Masuzaki, S.; Hashimoto, F.; Uto, T.; Tanigawa, S.; Fujii, M.; Sakata, Y.; Arch. Biochem. Biophys. 2007, 460, 67.

13. Yamaguti-Sasaki, E.; Ito, L. A.; Canteli, V. C. D.; Ushirobira, T. M. A.; Ueda-Nakamura, T.; Dias Filho, B. P.; Nakamura, C. V.; Mello, J. C. P.; Molecules 2007, 12, 1950.

14. Nergard, C. S.; Diallo, D.; Inngjerdingen, K.; Michaelsen, T. E.; Matsumoto, T.; Kiyohara, H.; Yamada, H.; Paulsen, B. S.; J. Ethnopharmacol. 2005, 96, 255 .

15. Fan, J.; Ding, X.; Gu, W.; Food Chem. 2007, 102, 168.

16. Brasil, Ministério da Saúde, Agência Nacional de Vigilância Sanitária; Resolução de Diretoria Colegiada RDC 48 de 16.3.2004, Dispõe sobre o registro de medicamentos fitoterápicos, Diário Oficial da União: Brasília - DF, 2004.

17. Yousef, G. G.; Grace, M. H.; Cheng, D. M.; Belolipov, I. V.; Raskin, I.; Lila, M. A.; Phytochemistry 2006, 67, 2380.

18. Benavides, A.; Montoro, P.; Bassarello, C.; Piacente, S.; Pizza, C.; J. Pharm. Biomed. Anal. 2006, 40, 639.

19. Lucena, R.; Cárdenas, S.; Gallego, M.; Valcárcel, M.; J. Chromatogr., A 2005, 1081, 127.

20. Lopes, G. C.; Sanches, A. C. C.; Toledo, C. E. M.; Isler, A. C.; Mello, J. C. P.; Braz. J. Pharm. Sci. 2009, 45, 135.

21. Lopes, G. C.; Rocha, J. C. B.; Almeida, G. C.; Mello, J. C. P.; J. Braz. Chem. Soc. 2009, 20, 1103.

22. Prodanov, M. P.; Domínguez, J. A.; Blázquez, I.; Salinas, M. R.; Alonso, G. L.; Food Chem. 2005, 90, 585.

23. Romani, A.; Ieri, F.; Turchetti, B.; Mulinacci, N.; Vincieri, F. F.; Buzzini, P.; J. Pharm. Biomed. Anal. 2006, 41, 415.

24. Brasil, Ministério da Saúde, Agência Nacional de Vigilância Sanitária; Resolução Específica (RE) 899 de 29 de maio de 2003, Determina a publicação do Guia para validação de métodos analíticos $e$ bioanalíticos, Diário Oficial da União: Brasília - DF, 2003.

25. ICH; Topic Q2B, Validation of Analytical Procedures: Methodology (CPMP/ICH/281/95), Step 4, Consensus Guideline, The European Agency for the Evaluation of Medicinal Products, 6 Nov 1996.

26. Lopes, G. C.; Bruschi, M. L.; Mello, J. C. P.; Chromatographia 2009, $69, \mathrm{~S} 175$

27. Yao, L.; Jiang, Y.; Datta, N.; Singanusong, R.; Liu, X.; Duan, J.; Raymont, K.; Lisle, A.; Xu, Y.; Food Chem. 2004, 84, 253.

28. Svedstrom, U.; Vuorela, H.; Kostiainen, R.; Laakso, I.; Hiltunen, R.; J. Chromatogr., A 2006, 1112, 103.

29. Dalluge, J. J.; Nelson, B. C.; Thomas, J. B.; Sander, L. C.; J. Chromatogr., A 1998, 793, 265. 